\title{
EDITORIAL
}

\section{A FILOSOFIA NA AMÉRICA LATINA}

Inegavelmente a característica mais marcante no que se refere ao pensamento latino-americano é a busca pela originalidade. Os pensadores da chamada "geração dos patriarcas" forjaram uma filosofia genuinamente latino-americana. A "geração dos forjadores", dominou a filosofia europeia e fezsucumbir o desnível técnico em relação a esta. Só então, partindo deste grande esforço das gerações anteriores, é que o grupo generacional se viu confrontado com a árdua missão de produzir um pensamento original que respondesse aos problemas do homem latino-americano.

Diante deste grande desafio, os filósofos latino-americanos assumiram posturas distintas, é o que alguns intelectuais presentes nesta nova edição da Revista Dialectus procuraram entender. Em caráter de Sumário, explanaremos um pouco dos textos que compõem este número. Sempre na expectativa de "seduzir" o leitor a encarar frontalmente os textos e extrair deles o seu devido julgamento.

Alejandro Rosillo Martínez em seu artigo Crítica a la Modernidad y Derechos Humanos desde la Filosofía de Ignacio Ellacuríaanalisaumconceito chave dafilosofia dalibertação de Ignacio Ellacuría, atravésdeuma crítica a modernidade que o mesmo denomina de“civilização da pobreza”. Antonio Salamanca emFilosofía Jurídica Latino Americana en el siglo XXI. La (Re)insurgencia Históricadel Derechodelos Pobresy la Naturaleza: ellusmaterialismopretende contribuir coma resposta a pergunta: comosair do estado atual de alienação e indigência ideológico-jurídica na América Latina noséculo XXI? Uma das respostas apela a urgência do empoderamento, a (re)insurgencia, do paradigma jurídico libertador própio dos pobres e da natureza: oiusmaterialismo. SebastiãoRodrigues Gonçalves em Da Formulação dos ConceitosaosReforços dos Preconceitosvisa analisar, entre tantos outros conceitos, os de superioridade e inferioridade relativos aos processos de legitimação da subordinação entre os nativos e os europeus, desde um processo histórico latino-americano. ClaudineiAparecido de Freitas da Silva em seu escrito O Lugar da Interpelação Ética: o Colóquio Dussel/Velascoretoma um debate ainda em curso acerca do estatuto último da interpelação ética no contexto de uma filosofia da libertação aberta por Dussel e reorientada criticamente por Sirio Lopez Velasco. Sua análise centrou-se no modelo velasquiano de uma "ética argumentativa" fundada à luz de três normas transcendentais tendo na perspectiva do "ecomunitarismo" seu horizonte utópico, por excelência. 
Gabriel Vargas Lozano em La Filosofía de la Praxis. Dos Concepciones: Antonio Gramsciy Adolfo Sánchez Vázquez trazumaconfrontação de dois importantes filósofos antifascistas que comportamas teses da la filosofía de Marx como uma “filosofía dapráxis", Gramsci e Vázquez. Thierno Diop em Le SocialismeBolivarien $d u$ XXI Siècleanalisa o socialismo bolivariano implementado por Hugo Chávez na Venezuela. Este socialismo, segundo o autor, se apresentacomo umacontinuaçãodo pensamento de Karl Marx, Lenin e Mao Tsé-Tung, contudo, depurado de suas formas pervertidas. Sirio López Velasco em seu artigo Notas para uma Estética Ecomunitaristana América Latinapretende explicitar as bases para uma proposta estética mínima através da ótica ecomunitarista. Seu itinerário filosófico segueas bases da teoriaecomunitarista para depoisintroduzirsuavisão dos conceitos básicos da estética e de suaaplicaçãoem diversas modalidades da produção artística, desde a vivência latinoamericana.

NaseçãoFluxocontínuo, temos o artigo de Maximiliano Dacuy intitulado La Construcción de Objetividad en la Filosofia de Ludwig Feuerbach, en el periodo 1841 - 1843.O propósito do presente trabalhoé indagar sobre a construção daobjetividade por parte de Ludwig Feuerbach no período de1839 a 1843. Para Agemir Bavaresco emIdealismo da Infinitude Hegeliana e Fetichismo da Finitude Marxianaa filosofia, a partir de Hegel e Marx, é um processo de apresentação da finitude abstrata imediata e da infinitude concreta mediata. Francisco de Assis Sobrinho e Marly Carvalho Soares no artigo O Problema da Desigualdade Social na Sociedade Civil e a Proposta de Superação no Estado Hegeliano tem como propósitoexplicitar, a partir da relação entre riqueza e pobreza, como se origina a desigualdade social no contexto da sociedade civil em Hegel, bem como, compreender como se dá sua superação no âmbito do Estado hegeliano. Renato SombergPfeffer em Filosofia do Diálogo: Aproximações entre Hannah Arendt e Emmanuel Lévinas tem por objetivo analisar a natureza crítica da obra desses pensadores acerca do caráter ontológico e contemplativo da Filosofia Ocidental. Valdênia Lourenço de Sousa e Frederico Jorge Ferreira Costa em Política de Assistência Social e Povos Indigenas: Limites e Possibilidades para Trabalho Social com Família tem por intuito apresentar a lacuna existente entre as diretivas legais e a efetivação equitativa da assistência social direcionada aos indígenas.

\begin{tabular}{|l|l|l|l|l|}
\hline Qevista Dialectus & Ano 5 & n. 13 & Agosto - Dezembro 2018 & p. 1 - 3 \\
\hline
\end{tabular}


Eduardo Ferreira Chagas / Sirio López Velasco / Manoel Jarbas Vasconcelos Carvalho.

Para finalizarmos a $13^{\text {a }}$ edição da Revista Dialectus contamos com a traduçãode Amsterdan Duarte do texto de Albert Camus intitulado: La Démocracieexercise de la modestie. Apósesse breve inventário, os organizadores esperam ter cumprido, a contento, a tarefa de apresentarminimamente os objetivos dos artigosaqui presentes e, umpoucomais, a saber: "despertar o interesse pela leitura".

Fortaleza, dezembro de 2018.

Eduardo Ferreira Chagas.

Sirio López Velasco.

Manoel Jarbas Vasconcelos Carvalho.

\begin{tabular}{|l|l|l|l|c|}
\hline Q Rovista Qialectus & Ano 5 & n. 13 & Agosto - Dezembro 2018 & p. 1-3 \\
\hline
\end{tabular}

